\title{
Fast and Selective Modification of Thiol Proteins/Peptides by $N$-(Phenylseleno) phthalimide
}

\author{
Zhengfang Wang, ${ }^{1}$ Yun Zhang, ${ }^{1}$ Hao Zhang, ${ }^{2}$ Peter B. Harrington, ${ }^{1}$ Hao Chen ${ }^{1}$ \\ ${ }^{1}$ Center for Intelligent Chemical Instrumentation, Department of Chemistry and Biochemistry, Ohio University, Athens, OH \\ 45701, USA \\ ${ }^{2}$ Department of Chemistry, Washington University, St. Louis, MO 63130, USA
}

\begin{abstract}
We previously reported that selenamide reagents such as ebselen and $\mathrm{N}$-(phenylseleno) phthalimide (NPSP) can be used to selectively derivatize thiols for mass spectrometric analysis, and the introduced selenium tags are useful as they could survive or removed with collisioninduced dissociation (CID). Described herein is the further study of the reactivity of various protein/peptide thiols toward NPSP and its application to derivatize thiol peptides in protein digests. With a modified protocol (i.e., dissolving NPSP in acetonitrile instead of aqueous solvent), we found that quantitative conversion of thiols can be obtained in seconds, using NPSP in a slight excess amount (NPSP:thiol of 1.1-2:1). Further investigation shows that the thiol reactivity toward NPSP reflects its chemical environment and accessibility in proteins/peptides. For instance, adjacent basic amino acid residues increase the thiol reactivity, probably because they could stabilize the thiolate form to facilitate the nucleophilic attack of thiol on NPSP. In the case of creatine phosphokinase, the native protein predominately has one thiol reacted with NPSP while all of four thiol groups of the denatured protein can be derivatized, in accordance with the corresponding protein conformation. In addition, thiol peptides in protein/peptide enzymatic digests can be quickly and effectively tagged by NPSP following tri- $n$-butylphosphine (TBP) reduction. Notably, all three thiols of the peptide QCCASVCSL in the insulin peptic digest can be modified simultaneously by NPSP. These results suggest a novel and selective method for protecting thiols in the bottom-up approach for protein structure analysis.
\end{abstract}

Key words: $N$-(phenylseleno)phthalimide, Derivatization, Thiol protein/peptide, Mass spectrometry, Reactivity

\section{Introduction}

Cysteine (abbreviated as Cys or $\mathrm{C}$ ), which contains a thiol group (-SH), is unique among 20 natural amino

Electronic supplementary material The online version of this article (doi:10.1007/s13361-011-0317-3) contains supplementary material, which is available to authorized users.

Correspondence to: Peter Harrington; e-mail: peter.harrington@ohio.edu, Hao Chen; e-mail: chenh2@ohio.edu acids and has biological significance. For example, cysteine defines protein structure via forming covalent disulfide bond linkages. In addition, cysteine-containing peptides and proteins, such as glutathione (GSH) are critical physiological components directly or indirectly related to many important biological phenomena, including cellular antioxidant defenses and redox signaling, modulation of various cellular activities, and so forth $[1,2]$. To facilitate the structure analysis of proteins, disulfide bond linkages are normally reduced [3, 4]. However, because the resulting thiols are readily oxidized back to disulfides [5], derivatization of thiol 
groups with a suitable chemical reagent is necessary for increasing thiol stability and improving detection selectivity.

Traditional approaches of protecting free cysteines in solution are based on thiol alkylation, Michael-addition, or thiol/disulfide exchange, but each of them has some limitations. The alkylation of protein thiols using $N$-ethylmaleimide or iodoacetamide is not specific toward thiols [3, 6]. Typically, these reactions require an excess amount of derivatizing reagent (1- to 1,000-fold molar excess) and a long reaction time $(15 \mathrm{~min}-8 \mathrm{~h})[6,7]$. For the Michaeladdition reaction, it refers to the addition of thiols to $\alpha, \beta$ unsaturated carbonyl and related compounds. Although it is selective to thiols [8-10], the reaction is irreversible and takes time. In addition, reversible thiol/disulfide exchange reactions serve to oxidize one thiol while reducing one disulfide [11]. This dynamic process is random and nondirected. Therefore, the formation of undesired disulfides is often seen [12]. Our cysteine-specific tagging strategy is the selective selenylation of thiols using selenamide reagents. In our recent study, cysteines in peptides and proteins were successfully derivatized by two selenamide reagents, 2phenyl-1,2-benzisoselenazol-3(2H)-one (ebselen) and $\mathrm{N}$ (phenylseleno)phthalimides (NPSP) [13]. Among 20 amino acids, only cysteine is reactive toward the selenamide reagents. We also found that the phenylselenenyl tag (PhSe-) added to the cysteine residue via the NPSP derivatization can survive collision-induced dissociation (CID), which is useful in sequencing peptides and locating cysteine residues [14]. However, the selenium tag introduced through ebselen derivatization can be lost during CID to form the protonated ebselen, providing a quick screening method for selective detection of cysteinecontaining proteins from mixtures using precursor ion scan by mass spectrometry (MS) [14].

In this work, in consideration of the instability of NPSP in aqueous solution that actually decreases its efficiency in thiol derivatization, a new protocol was adopted to acquire a high conversion yield, in which a freshly prepared NPSP in anhydrous acetonitrile was used to react with thiol substrates for the modification. We further investigated the thiol reactivity toward NPSP and explored the related analytical applications of this modification reaction. This study shows that (1) the NPSP selenylation reaction occurs to thiol peptides and proteins rapidly, selectively and quantitatively within seconds, and the reaction products are stable at room temperature in acidic solution ( $\mathrm{pH} 2.5-6$ ), suggesting that NPSP is a premium reagent for thiol derivatization; (2) the reactivities of thiols depend on the acidities of their adjacent amino acid residues as well as their accessibility, providing an approach to probe protein conformational structure; (3) thiol peptides in enzymatic digests of proteins/peptides can be rapidly and effectively modified by NPSP, indicating the potential utility of this reaction in bottom-up proteomic approaches.

\section{Experimental}

\section{Chemicals}

$\beta$-Lactoglobulin A from bovine milk (lyophilized powder), bovine serum albumin (lyophilized powder, MW $\sim 66 \mathrm{kDa}$ ), human hemoglobin (lyophilized powder, MW 64,500 Da), creatine phosphokinase from rabbit muscle (lyophilized powder, MW $\sim 81 \mathrm{kDa}$ ), insulin from bovine pancreas (lyophilized powder), pepsin from porcine gastric mucosa (lyophilized powder), NPSP, tri- $n$-butylphosphine (TBP, 97\%), and $N, N$-dimethylformamide (anhydrous DMF, 99.8\%) were all purchased from Sigma-Aldrich (St. Louis, MO, USA). Peptides Cys-Gly (CG, MW 178.2 Da), glutathione (GSH, reduced form, MW 307.3 Da), His-Cys-Lys-Phe-Trp-Trp (HCKFWW, MW 906.1 Da), and Cys-Gln-Asp-Ser-Glu-ThrArg-Thr-Phe-Tyr (CQRSETRTFY, MW 1249.3 Da) were all purchased from TCI America (Tokyo, Japan). Peptide [ $\left.\mathrm{Arg}^{8}\right]-$ conopressin G (sequence CFIRNCPRC with one disulfide bond bridging the two cysteines; MW $1062.3 \mathrm{Da}$ ) was purchased from Bachem (King of Prussia, PA, USA).

HPLC-grade methanol and acetonitrile (ACN) from GFS Chemicals (Columbus, OH) and Sigma-Aldrich (St. Louis, MO) were used and acetic acid (HOAc) was purchased from Fisher Scientific (Pittsburgh, PA, USA). The de-ionized water used for sample preparation was obtained using a Nanopure Diamond Barnstead purification system (Barnstead International, Dubuque, IA, USA).

\section{NPSP Derivatization}

Unless specified otherwise, the protein/peptide samples were typically dissolved in $\mathrm{ACN}: \mathrm{H}_{2} \mathrm{O}: \mathrm{HOAc}$ (49.5:49.5:1, v:v: $\mathrm{v}$; denoted as solvent A). The NPSP solution was freshly prepared by adding anhydrous ACN to NPSP powder, and then added to the peptide/protein samples to effect derivatization. After vortexing the reaction mixture for $15 \mathrm{~s}$, the resulting solution was analyzed by MS.

In the case of creatine phosphokinase, for the reaction with the protein under native conditions, a $40 \mu \mathrm{M}$ creatine phosphokinase in $20 \mathrm{mM} \mathrm{NH}_{4} \mathrm{OAc}$ solution was mixed with $1 \mu \mathrm{L}$ of $24 \mathrm{mM}$ NPSP in ACN. For the reaction with the protein under denaturated conditions, a $30 \mu \mathrm{L}$ of $40 \mu \mathrm{M}$ creatine phosphokinase in $\mathrm{MeOH}: \mathrm{H}_{2} \mathrm{O}: \mathrm{HOAc}$ (49.5:49.5:1, v:v:v) was reacted with $1 \mu \mathrm{L}$ of $24 \mathrm{mM}$ NPSP in ACN. The reacted proteins were desalted using Vivaspin $5000 \mathrm{MWCO}$ PES prior to MS analysis.

\section{Protein/Peptide Digestion}

Digestion of insulin was carried out using pepsin. A $558 \mu \mathrm{L}$ aliquot of $0.5 \mathrm{mM}$ insulin in $0.5 \%$ (v:v) formic acid (FA) $/ \mathrm{H}_{2} \mathrm{O}$ was mixed with $19.5 \mu \mathrm{L}$ of $0.29 \mathrm{mM}$ pepsin in $\mathrm{H}_{2} \mathrm{O}$, to reach a molar ratio of 50:1 (insulin:pepsin). The solution was incubated at $37{ }^{\circ} \mathrm{C}$ for $6.5 \mathrm{~h}$. Digestion of $\left[\mathrm{Arg}^{8}\right]$-conopressin $\mathrm{G}$ was carried out using trypsin. A $1000 \mu \mathrm{L}$ of $0.1 \mathrm{mM}\left[\mathrm{Arg}^{8}\right]$ - 
conopressin $\mathrm{G}$ in $25 \mathrm{mM} \mathrm{NH} \mathrm{HCO}_{3}$ aqueous solution was mixed with $50 \mu \mathrm{L}$ of $0.1 \mathrm{mM}$ trypsin in $\mathrm{H}_{2} \mathrm{O}$. The mixture was incubated at $37{ }^{\circ} \mathrm{C}$ for $16 \mathrm{~h}$. The resulting digest solutions were diluted 10 times using solvent A before MS analysis.

\section{Reduction of Enzymatic Digests}

To reduce the disulfide bonds of peptides in the insulin digest, $5 \mu \mathrm{L}$ of $0.15 \%$ TBP in DMF was added to $100 \mu \mathrm{L}$ of $10 \mu \mathrm{M}$ protein digest, according to the literature [15]. The mixture was vortexed for $1 \mathrm{~h}$ at room temperature. Then, the resulting mixture was dried at $60{ }^{\circ} \mathrm{C}$ using a vacuum concentrator to remove the excess volatile TBP. The vacuum was released after the temperature cooled down to room temperature and the protein was redissolved in $100 \mu \mathrm{L}$ of solvent A. Finally, a $100 \mu \mathrm{L}$ of $10 \mu \mathrm{M}$ reduced digested insulin solution was mixed with $100 \mu \mathrm{L}$ of $100 \mu \mathrm{M}$ NPSP in anhydrous ACN for derivatization.

\section{Mass Spectrometric Analysis}

Electrospray ionization (ESI) or electrosonic spray ionization (ESSI [16], a variant form of ESI) was used for analysis of the reacted protein/peptide products. ESSI-MS spectra were recorded in the positive ion mode on a Thermo Finnigan LCQ DECA Mass Spectrometer (San Jose, CA, USA) equipped with a home-built ESSI source. A $+5 \mathrm{kV}$ high voltage was used for ESSI and the nebulizing gas $\left(\mathrm{N}_{2}\right)$ was kept at 180 psi. The sample injection flow rate was $3-$ $5 \mu \mathrm{L} / \mathrm{min}$. The heated capillary temperature was $150{ }^{\circ} \mathrm{C}$. CID was used for structural confirmation of the assigned product ions. Data acquisition was performed using Xcalibur (rev. 2.0.7, Thermo Scientific, San Jose, CA, USA). Deconvolution of mass spectra was carried out using MagTran $1.03 \mathrm{~b} 2$ software based on the ZScore algorithm [17].

The ESI-MS spectra of creatine phosphokinase samples were collected using a Bruker MaXis Q-TOF mass spectrometer (Bremen, Germany) in the positive ion mode. The capillary voltage was $4.5 \mathrm{kV}$, nebulizer gas was 0.4 bar, dry gas was $4.0 \mathrm{~L} / \mathrm{min}$, and the source temperature (dry temperature) was $180{ }^{\circ} \mathrm{C}$.

\section{Safety Precaution}

As TBP and NPSP are harmful in contact with skin, swallowed, or inhaled, a cold trap was used to condense the TBP vapor during the vacuum evaporation of the reduced protein digests.

\section{Results and Discussion}

\section{Derivatization of Various Protein/Peptide Thiols}

In our previous experiment [13], NPSP was first prepared in $\mathrm{ACN} / \mathrm{H}_{2} \mathrm{O} / \mathrm{HOAc}$ to reach the desired concentration, and then mixed with protein/peptide thiols for reaction. In the case of glutathione (GSH, sequence $r$-ECG), GSH was not completely derivatized even when NPSP used was in 5-fold excess.[13] It is very likely that NPSP degraded in the original reagent solution containing water. Indeed, we noticed that the NPSP gradually develops a yellow color in the aqueous solution with time. To circumvent this issue, in this study, NPSP was freshly prepared in anhydrous ACN and then used for derivatizing thiols. Various thiol peptides and proteins were chosen to evaluate the efficiency of the derivatization reaction by NPSP using this new protocol. In the experiment, MS spectra were acquired $15 \mathrm{~s}$ after mixing NPSP solution with protein/peptide samples.

Figure 1a is the ESSI-MS spectrum of the reaction products after mixing NPSP $(11 \mu \mathrm{M}$ in $\mathrm{ACN})$ with GSH $(10 \mu \mathrm{M}$ in solvent $\mathrm{A})$. We found that GSH was completely derivatized and there was no longer a peak at $\mathrm{m} / \mathrm{z} 308$ in the spectrum corresponding to the protonated GSH. Instead, a dominant peak at $\mathrm{m} / \mathrm{z} 464$ corresponding to the protonated NPSP-derivatized GSH ion $[r \text {-EC* } \mathrm{G}+\mathrm{H}]^{+}$appears (the labeling asterisk $*$ indicates a derivatized cysteine with a PhSe tag; see the reaction equation in the Figure 1a inset). A mass shift of $156 \mathrm{Da}$ occurring for this peptide ion after derivatization agrees with the addition of one phenylselenenyl tag PhSe- to GSH containing only one free thiol. The characteristic selenium isotope distribution of the derivatized GSH ion helps verify its identification. Also, upon CID of $\mathrm{m} / \mathrm{z} 464$, backbone cleavages (the formation of $m / z 318,335$, and 389) as well as water loss (the formation of $\mathrm{m} / \mathrm{z}$ 446) were observed, confirming the product ion structure and the covalent nature of the newly formed Se-S bond in the derivatized peptide. Therefore, one can see that the new protocol of NPSP derivatization does enhance the reaction efficiency, in which quantitative conversion of thiols with a slightly excess amount of NPSP is possible.

The stability of the derivatized peptide products was also examined. It was found that the derivatized GSH was stable (as tested by ESI-MS) after 2-d storage at room temperature at a $\mathrm{pH}$ of 2.5-6.0. However, when the $\mathrm{pH}$ of the product solution was adjusted to a $\mathrm{pH}$ of 10 , the derivatized peptide was not stable and the ion at $m / z 464$ was no longer apparent in the acquired mass spectrum.

Using the new protocol, we further reacted NPSP with a thiol peptide mixture composed of HCKFWW, CQRSETRTFY, $\mathrm{CG}$, and GSH. Figure $1 \mathrm{~b}$ is the ESSI-MS spectrum of the original peptide mixture, in which +1 or +2 peptide ions are present. After the modification using NPSP (Figure 1c), the ions of all derivatized peptides $[\mathrm{HC} * \mathrm{KFWW}+\mathrm{H}]^{2+}(\mathrm{m} / \mathrm{z} 532)$, $[\mathrm{HC} * \mathrm{KFWW}+\mathrm{H}]^{+}(m / z$ 1062 $), \quad\left[\mathrm{C}^{*} \mathrm{QRSETRTFY}+\mathrm{H}\right]^{2+}$ $(m / z \text { 703), [C* } \mathrm{QRSETRTFY}+\mathrm{H}]^{+}\left(\mathrm{m} / z\right.$ 1406), $\left[\mathrm{C}^{*} \mathrm{G}+\mathrm{H}\right]^{+}$ $(\mathrm{m} / \mathrm{z} 335)$, and $[r \text {-EC* } \mathrm{G}+\mathrm{H}]^{+}(\mathrm{m} / z$ 464) were observed. The identities of these ions were confirmed by CID (data not shown). In addition, peaks corresponding to the intact peptide ions such as $[\mathrm{HCKFWW}+\mathrm{H}]^{+}(\mathrm{m} / z \text { 906), [CQRSETRTFY }+\mathrm{H}]^{+}$ $(m / z 1250),[\mathrm{CG}+\mathrm{H}]^{+}\left(m / z\right.$ 179), and $[r-\mathrm{ECG}+\mathrm{H}]^{+}(m / z 308)$ 

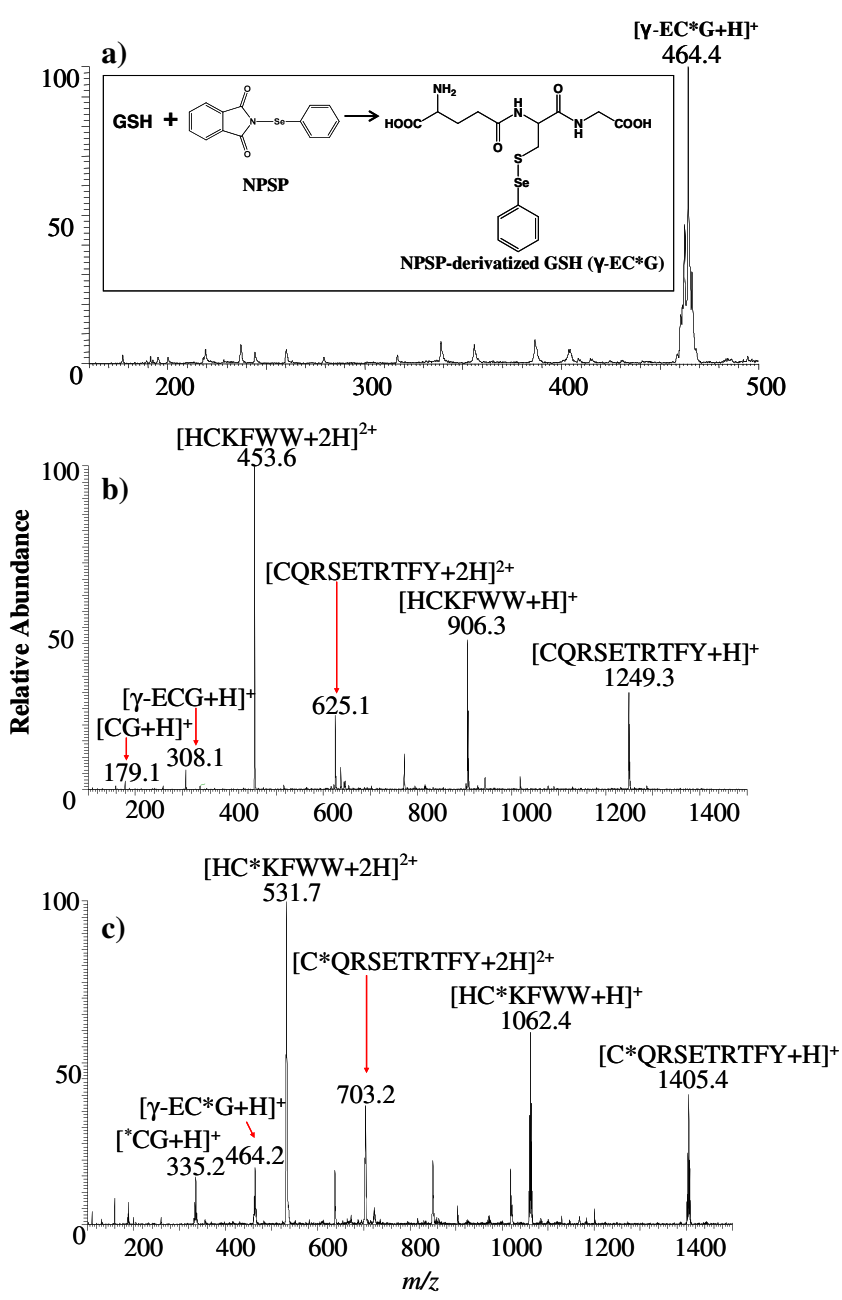

Figure 1. (a) ESSI-MS spectrum showing the products from the NPSP derivatization of GSH via mixing $100 \mu \mathrm{L}$ of $11 \mu \mathrm{M}$ NPSP in anhydrous ACN with $100 \mu \mathrm{L}$ of $10 \mu \mathrm{M} \gamma$-ECG prepared in solvent $A$ for $15 \mathrm{~s}$. (b) ESSI-MS spectrum of $100 \mu \mathrm{L}$ of HCKFWW/CQRSETRTFY/CG/Y-ECG (10 $\mu \mathrm{M}$ each) in solvent A. (c) ESSI-MS spectrum showing the products from the NPSP derivatization of a peptide mixture via mixing $100 \mu \mathrm{L}$ of $44 \mu \mathrm{M}$ NPSP in anhydrous ACN with $100 \mu \mathrm{L}$ of HCKFWW/CQRSETRTFY/CG/Y-ECG (10 $\mu \mathrm{M}$ each) in solvent $A$ for $15 \mathrm{~s}$. Note that the asterisk * labeling indicates a PhSe- tag

were not observed, indicating that all of these thiol peptides had been reacted with NPSP. These results further demonstrate the complete tagging of all free cysteines of peptides in mixtures, even with nearly stoichiometric amount of NPSP (NPSP:thiol of 1.1:1). Note that there are some unlabeled peaks in Figure $1 \mathrm{~b}$ and c. These ions arose from background contamination as determined by the analysis of blank samples.

To go a step further, three representative thiol proteins were used as substrates to react with NPSP. The first case was $\beta$-lactoglobulin A from bovine milk. Being a common variant of $\beta$-lactoglobulin, $\beta$-lactoglobulin $A$ contains one free thiol group at $\mathrm{Cys}^{121}$ and two disulfide bonds at $\mathrm{Cys}^{66}$ $\mathrm{Cys}^{160}$ and $\mathrm{Cys}^{106}{ }^{10 y s}{ }^{119}$. Figure 2a displays the ESSI-MS spectrum of $10 \mu \mathrm{M} \beta$-lactoglobulin $\mathrm{A}$ in solvent $\mathrm{A}$ and Figure $2 \mathrm{~b}$ is the ESSI-MS spectrum of $\beta$-lactoglobulin A $(10 \mu \mathrm{M}$ in solvent A) reacted with NPSP $(20 \mu \mathrm{M}$ in $\mathrm{ACN})$. In the deconvoluted spectra (insets of Figure 1a and b), the mass difference between untagged and tagged protein ions is $155 \mathrm{Da}$, indicating the addition of a PhSe- tag to the sole free cysteine site of the protein (the theoretical shift is $156 \mathrm{Da}$ and the small mass discrepancy of 1 Da may be caused by a mass error in measuring multiply charged protein ions by our LCQ instrument with low mass resolution). For the second case, a much larger protein, bovine serum albumin (BSA, MW $\sim 66 \mathrm{kDa}$ ) containing one free thiol group, was reacted with NPSP. Figure $2 \mathrm{c}$ is the ESSIMS spectrum of $10 \mu \mathrm{M}$ BSA in solvent A while Figure $2 \mathrm{~d}$ is the ESSI-MS spectrum of its derivatization product from reaction with NPSP. Again, a mass shift of 157.5 Da appears after derivatization in the acquired spectra that indicates the tagging of the free thiol in BSA. Likewise, the deviation from the theoretical mass shift of $156 \mathrm{Da}$ is likely to be caused by the low resolution of our LCQ instrument.

Furthermore, human hemoglobin containing multiple free thiol groups was chosen to be reacted with NPSP. Human hemoglobin is a tetramer, consisting of two $\alpha$-chains and two $\beta$-chains; each $\alpha$-chain contains a single cysteine residue while each $\beta$-chain contains two [18]. Figure 2e is the ESSIMS spectrum of $10 \mu \mathrm{M}$ human hemoglobin (in solvent $\mathrm{A}$ ), in which multiply charged $\alpha$-chain and $\beta$-chain ions were observed under the denaturing condition. Figure $2 \mathrm{f}$ displays the ESSI-MS spectrum of derivatized human hemoglobin generated from the selenylation reaction of $100 \mu \mathrm{L}$ of human hemoglobin $10 \mu \mathrm{M}$ in solvent $\mathrm{A}$ and $100 \mu \mathrm{L}$ of NPSP $(65 \mu \mathrm{M}$ in $\mathrm{ACN})$. By comparison of the deconvoluted spectra before and after derivatization (insets of Figure 2e and $\mathrm{f}$ ), the $\alpha$-chain obtained one PhSe- tag and the $\beta$-chain had acquired two tags. This result is expected for the reason that there is only one free thiol group in the $\alpha$-chain but two free thiol groups in the $\beta$-chain. A high resolution ESI-MS profile was collected on a Bruker 12 Tesla FT-ICR mass spectrometer (illustrated in the inset of Figure 2f), the measured isotope peak distribution of +12 ion of the NPSP-derivatized $\beta$-chain (red dashed curve) matches the calculated isotope peak distribution of the corresponding ion (green solid curve), confirming the addition of two PhSetags onto the $\beta$-chain.

In a recent literature about selective modification of cysteine residues in hemoglobin using 5.8-fold excess amount of 1,4-naphthoquinone, the reaction mixture was allowed to react for $15 \mathrm{~min}$ and partially modified $\beta$ chain ions were observed [18]. In comparison, NPSP seems to be a more potent reagent than the Michael-addition reagent in modifying protein thiols. These examples of derivatized thiol proteins and peptides demonstrated that a slight excessive amount of NPSP (NPSP:thiol=1.1-2:1) could 

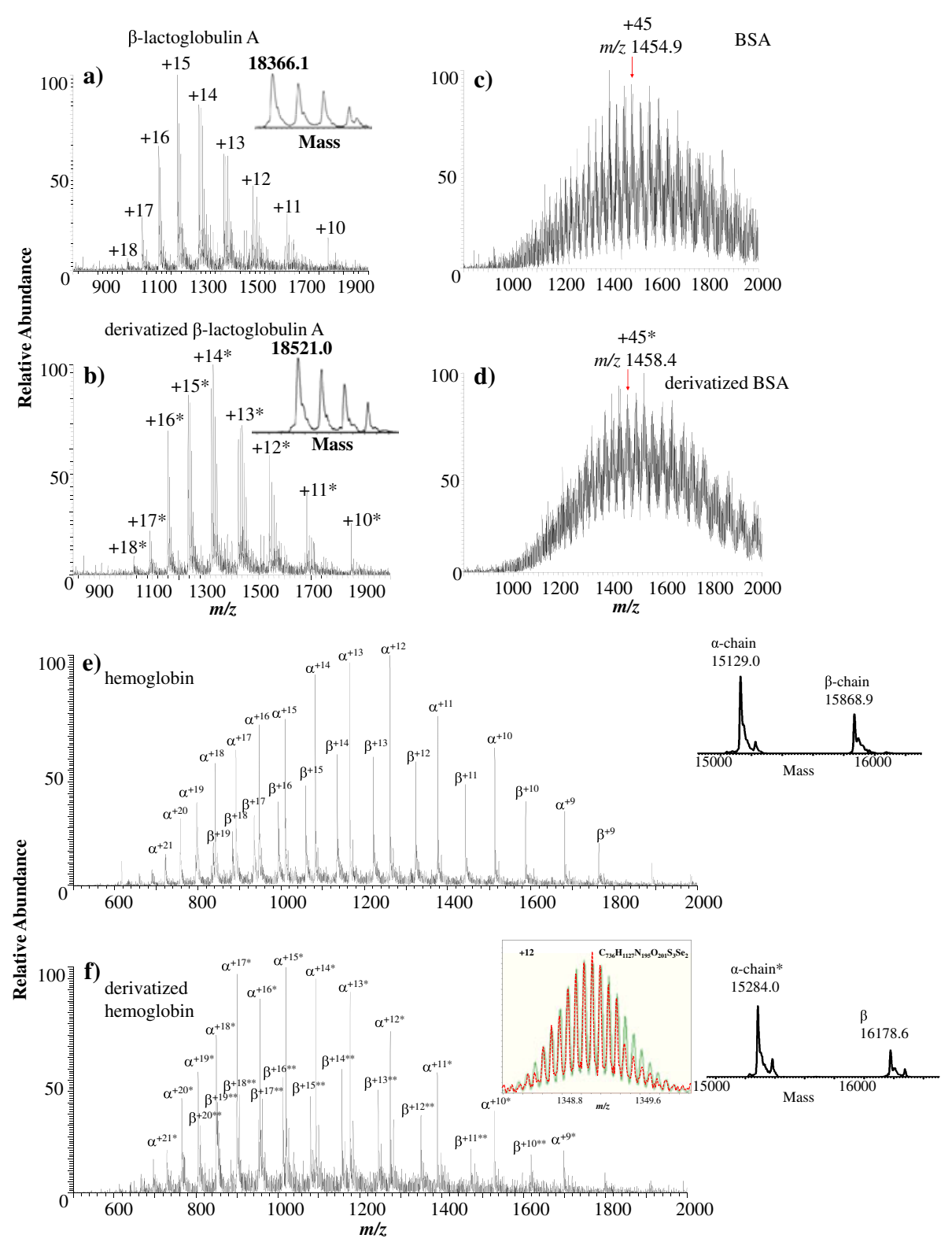

Figure 2. ESSI-MS spectra showing free thiol proteins of (a) $10 \mu \mathrm{M} \beta$-lactoglobulin $A$ in solvent $A$, (c) $10 \mu M B S A$ in solvent $A$, and (e) $10 \mu \mathrm{M}$ human hemoglobin in solvent A. ESSI-MS spectra containing the products of the NPSP derivatization of thiol proteins via (b) mixing $100 \mu \mathrm{L}$ of $20 \mu \mathrm{M}$ NPSP in anhydrous ACN with $100 \mu \mathrm{L}$ of $10 \mu \mathrm{M} \beta$-lactoglobulin A in solvent A, (d) mixing $100 \mu \mathrm{L}$ of $20 \mu \mathrm{M}$ NPSP in anhydrous $\mathrm{ACN}$ with $100 \mu \mathrm{L}$ of $10 \mu \mathrm{M}$ BSA in solvent $\mathrm{A}$, and (f) mixing $100 \mu \mathrm{L}$ of $65 \mu \mathrm{M}$ NPSP in anhydrous ACN with $100 \mu \mathrm{L}$ of $10 \mu \mathrm{M}$ human hemoglobin in solvent A. Note that two asterisks ${ }^{* *}$ refer to two PhSe- tags. The left inset of Figure $2 f$ gives the comparison between the measured isotope peak distribution of +12 NPSP-modified hemoglobin $\beta$-chain ion (red dashed curve) and the simulated isotope peak distribution of the corresponding ion (green solid curve). The two distributions overlap well

completely convert protein/peptide thiols, showing the high efficiency of the derivatization and the high reaction yield. The number of added tags agrees with that of the free thiols available in the proteins/peptides, indicating the high reaction specificity. The high selectivity is important and is consistent with our previous observation that among 20 amino acids, only cysteine is reactive to NPSP. Equally important, the time needed for derivatization is seconds, representing another advantage in comparison to other traditional thiol derivatization reagents such as alkylation or Michael-addition reagents.

NPSP-derivatized hemoglobin was further digested with pepsin, and MS/MS was used to identify the modification sites. The ESSI spectrum of the digest shows two derivatized peptide ions [KLLSHC*LL $+\mathrm{H}]^{+}$ $(m / z \quad 1082)$ and $[K L L S H C * L L+2 H]^{2+}(m / z$ 542; Figure 
1S-a, Supporting Information). CID of these ions indicates that the tags are located in the cysteine residues (Figures 1S-b and c, Supporting Information). This result confirms the high selectivity of NPSP toward cysteines, even in protein substrates.

\section{Probing Thiol Reactivity}

Thiol reactivity has attracted increasing attention [19]. Cysteine-specific chemical modification in conjunction with mass spectrometry can be a valuable way to obtain useful protein structural information [6]. It has been reported that solvent accessibility is not the only factor that controls cysteine reactivity, and certain relationships between the chemical environment of cysteine in a protein and its reactivity have been noted [6, 20]. Recently, globally profiling of cysteine reactivity in proteomes even showed that the most hyper-reactive cysteines were remarkably enriched in functional residues of proteins [19].

In this study, reactivities of different peptide thiols toward NPSP were investigated. In the experiment, an insufficient amount of NPSP was added to a thiol peptide mixture to generate a competition among different thiol peptides for NPSP (i.e., $100 \mu \mathrm{L}$ of $20 \mu \mathrm{M}$ NPSP in anhydrous ACN was added to $100 \mu \mathrm{L}$ of a mixture containing HCKFWW, CQRSETRTFY, CG, and GSH, $10 \mu \mathrm{M}$ each) in solvent A. As illustrated in Figure 3a, all the thiol peptides were partially derivatized because of insufficient NPSP in the solution (in contrast with the complete derivatization in Figure 1c). A reaction yield used to evaluate the thiol reactivity of thiol is defined as

$$
\frac{R A_{\text {reacted-peptide }}}{\left(R A_{\text {unreacted-peptide }}+R A_{\text {reacted-peptide }}\right)}
$$

for which $R A_{\text {unreacted- peptide }}$ is the relative abundance of the underivatized peptide ion and $R A_{\text {reacted- peptide }}$ is the relative

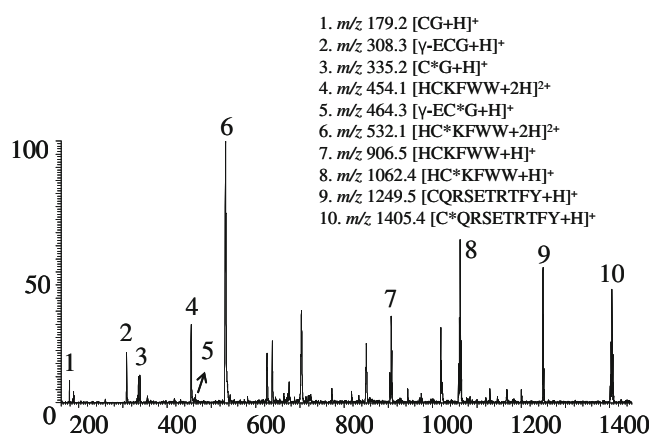

Figure 3. ESSI-MS spectrum of $100 \mu \mathrm{L}$ of $20 \mu \mathrm{M}$ NPSP in anhydrous ACN mixed with $100 \mu \mathrm{L}$ of a peptide mixture containing HCKFWW, CQRSETRTFY, CG, and GSH $(10 \mu \mathrm{M}$ each) in solvent $A$ abundance of the derivatized peptide ion. Under the same condition, the more derivatized peptide there is, the higher the ratio is, and the more reactive this peptide is. In this case, we did not take into account the change in the peptide ionization efficiency before and after derivatization, as the tag $\mathrm{PhSe}$ - is a relatively small neutral functional group in comparison to the peptides themselves. From this point of view, the thiol reactivity sequence (from high to low) is HCKFWW, CG, CQDSETRTFY, and GSH, as reported in Table 1.

We found that less reactive cysteines occur nearby acidic residues, which tend to suppress thiol dissociation and raise the $\mathrm{p} K_{\mathrm{a}}$ of the cysteine residues; on the contrary, if cysteine was adjacent to a basic amino acid, its reactivity would be enhanced. This phenomenon is in accordance with the previous report [6]. In our experiment, HCKFWW is more reactive than other thiol peptides toward NPSP, probably because of the factor that its cysteine residue is adjacent to a basic amino acid on both sides (His and Lys). GSH has the lowest reactivity toward NPSP because its cysteine residue is next to an acidic amino acid ( $r$-ECG). In the case of CG and CQDSETRTFY, both of their cysteine residues are adjacent to a neutral amino acid. CG is more reactive with NPSP than CQDSETRTFY probably because it has a much smaller size and, therefore, a much lower steric hindrance.

\section{Probing Protein Conformational Change}

Site-specific labeling with molecular probes in conjunction with MS detection can facilitate the visualization of protein conformational changes $[15,21,22]$. In this study, we present another experiment to study the reactivity of different cysteine residues in the same protein, which can provide clues to the protein conformational alteration.

Creatine phosphokinase (CK) was used in this experiment. CK is a dimer consisting of two identical subunits (see Figure 4d). In each subunit, there are four free cysteine residues, three of which are embedded inside the protein $\left(\mathrm{Cys}^{74}, \mathrm{Cys}^{146}\right.$, and $\mathrm{Cys}^{254}$ ) [23, 24]. According to the crystal structure of CK provided in Protein Data Bank (RCSB PDB), indeed, the total solvent accessibility areas calculated by the GETAREA software [25], for $\mathrm{Cys}^{74}$, $\mathrm{Cys}^{146}, \mathrm{Cys}^{254}$, and $\mathrm{Cys}^{283}$ are $0.00,2.21,4.10$, and $35.76 \AA^{2}$, respectively. From these data, $\mathrm{Cys}^{283}$ is the most accessible for derivatization. Figure $4 \mathrm{a}$ is the ESI-MS spectrum of intact CK protein in which the multiply charged ions +53 to +59 were detected. Figure $4 \mathrm{~b}$ is the ESI-MS spectrum of the derivatized CK protein from the reaction with NPSP under native conditions (in $20 \mathrm{mM}$ ammonium acetate). In Figure $4 \mathrm{~b}$, the ions of major products $+53^{*}$ to $+59^{*}$, arose, corresponding to the $\mathrm{CK}$ ions with one PhSetag. This result is in agreement with the previously reported result using the derivatizing reagent of methoxycarbonyl- 
Table 1. Thiol Peptide Reactivity Toward NPSP

\begin{tabular}{|c|c|c|c|c|c|}
\hline Peptides & \multicolumn{2}{|c|}{ Underivatized } & \multicolumn{2}{|c|}{ Derivatized } & 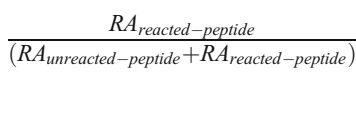 \\
\hline HCKFWW & 906.5 & 4.78 & 1062.4 & 16.00 & 0.77 \\
\hline CG & 179.2 & 1.96 & 335.2 & 1.99 & 0.51 \\
\hline CQRSETRTFY & 1249.5 & 13.80 & 1405.4 & 10.70 & 0.44 \\
\hline GSH $(\gamma-E C G)$ & 308.3 & 4.15 & 464.3 & 0.87 & 0.17 \\
\hline
\end{tabular}

$* \mathrm{RA}=$ the relative ion abundance

1,4-hydroquinone.[15] Also, minor product ions, the CK ions with two tags, also appear probably due to the modification of the $\mathrm{Cys}^{254}$, the second most accessible residue.

By contrast, upon denaturation in an acidic solvent containing methanol, the CK displayed different reaction behavior with NPSP. In the latter case, the CK protein ions with four PhSe- tags were observed and no underivatized or partially labeled CK ions were observed (Figure 4c). These results indicate that only one free thiol is most accessible in a native folded structure while all of the four thiols become accessible upon protein denaturation. The complete conversion of CK protein by NPSP after denaturation further shows the potency of this selenamide reagent in modifying thiols. Evidently, the thiol reactivities depend on protein conformation. It is therefore possible to monitor the protein conformational alteration by examining the number of thiols that can be derivatized by NPSP. It is advantageous to use a fast derivatizing reagent like NPSP for such a purpose, as undesirable conformational changes resulting from a long derivatization process needs to be avoided [26].

\section{Derivatization of Protein/Peptide Digests by NPSP Following Reduction}

Bottom-up approach is a common method to identify and sequence proteins by proteolytic digestion of proteins followed with MS analysis. In traditional protocols, disulfide bridges of peptides in the digest are first reduced using reducing agents such as dithiothreitol (DTT) and the resulting free thiols are protected via iodoacetamide derivatization. However, such a derivatization step usually takes half an hour. In consideration that NPSP tagging takes place in seconds with high selectivity and yield, it would be necessary to explore an alternative derivatization method using NPSP in

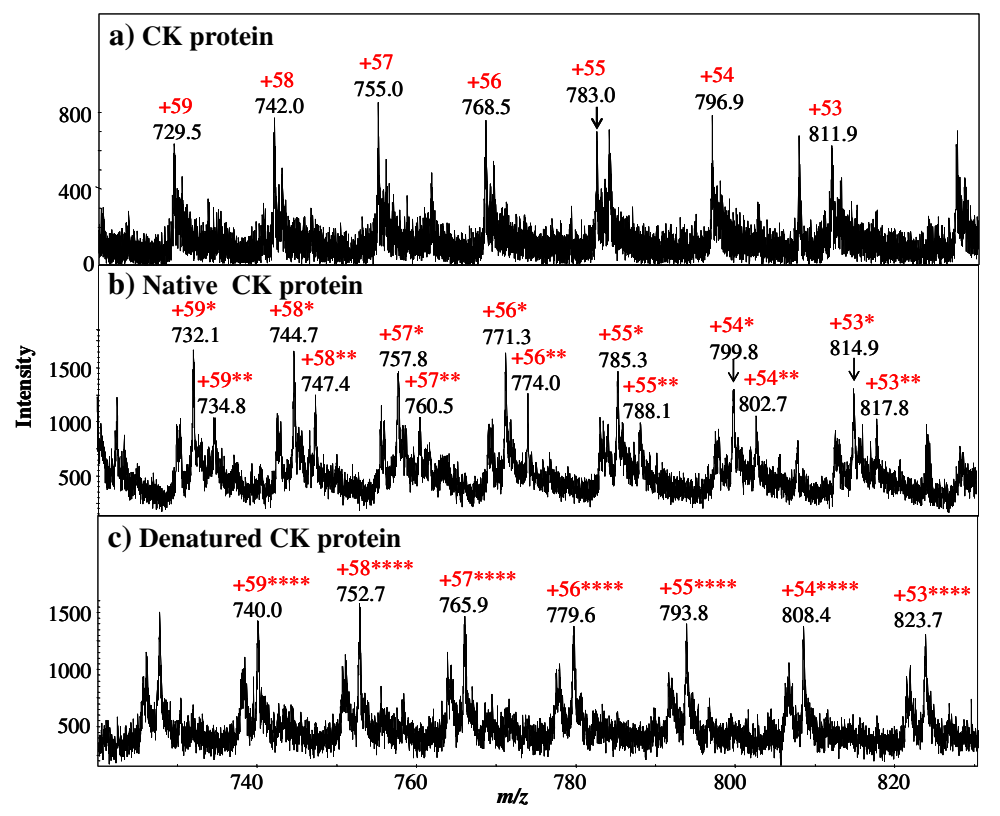

d)

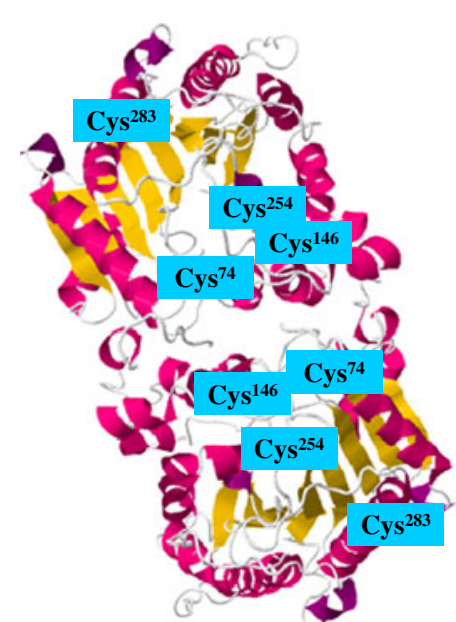

CK protein dimer

Figure 4. ESI-MS spectra of (a) intact creatine phosphokinase, (b) the creatine phosphokinase derivatized by NPSP under native conditions, and (c) the creatine phosphokinase derivatized by NPSP under denaturated conditions. (d) The crystal structure of the rabbit muscle creatine kinase [24] showing the four free cysteine residues in each monomer of the creatine phosphokinase was obtained from the RCSB Protein Data Bank and generated by PQS software (Jmol ver. 12.0.41) 

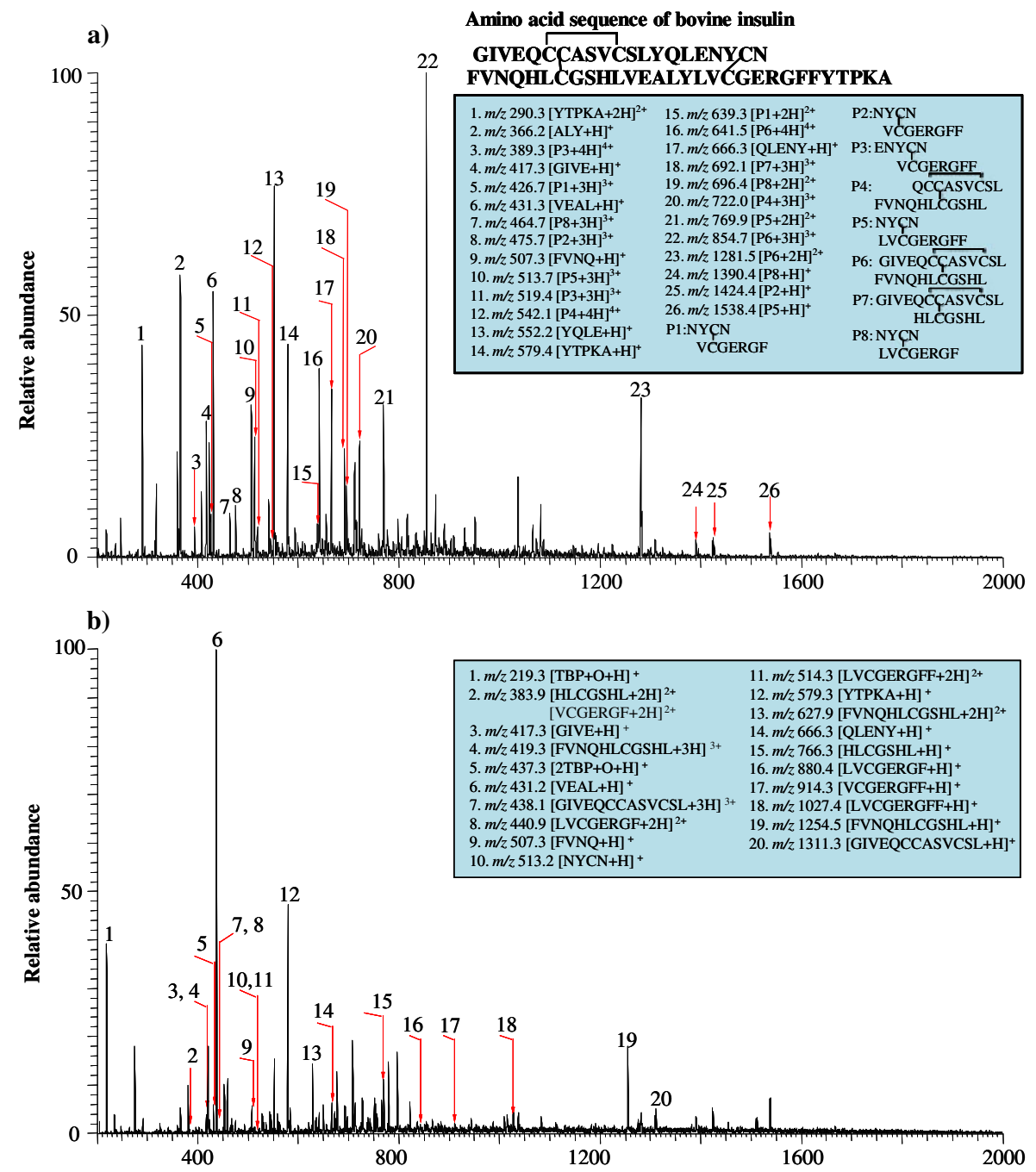

c) $\mathrm{x} 2 \longrightarrow$

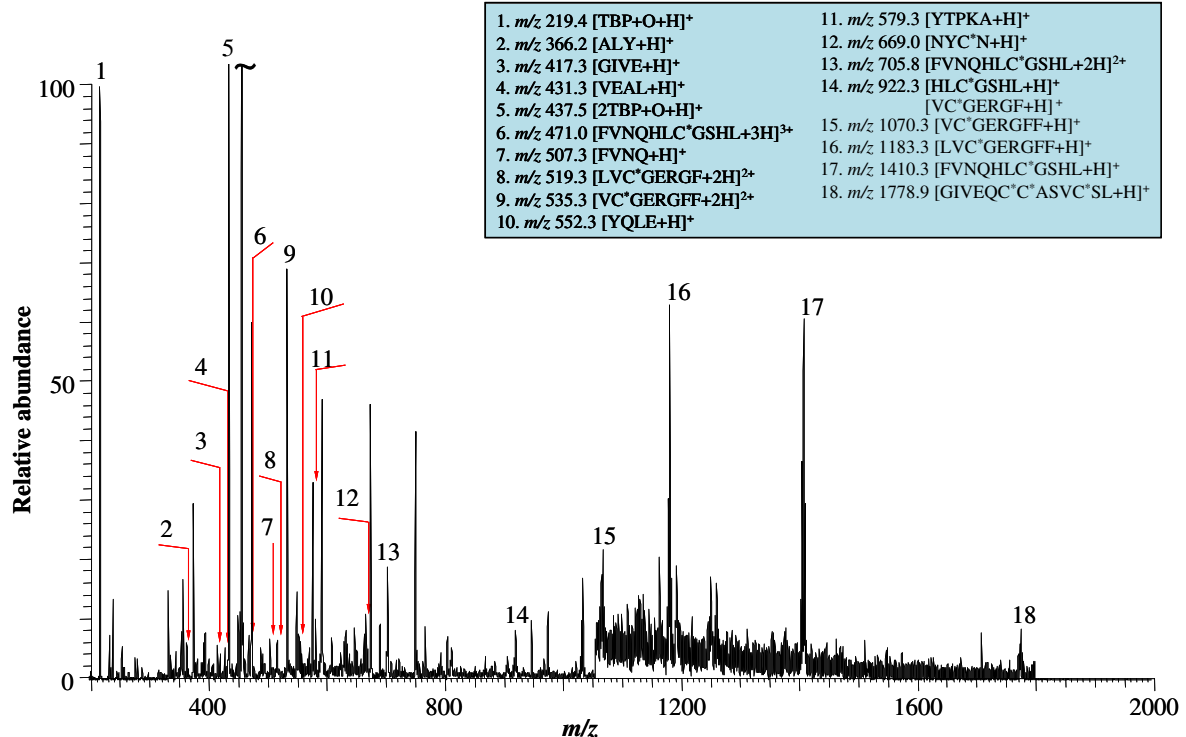

Figure 5. ESSI-MS spectra of (a) the pepsin-digested insulin, (b) the insulin digest after TBP reduction, and (c) the reduced insulin digest after NPSP derivatization 
the bottom-up approach. However, it is challenging to derivatize thiols by NPSP in the presence of excess amount of reductants because chemical reductants can also reduce $\mathrm{Se}-$ $\mathrm{S}$ bond[13] (i.e., the NPSP-derivatized peptide products). One has to remove the excess reductant prior to the addition of NPSP into the digest samples for derivatization and removal of reductant such as DTT from the digests could be troublesome. To overcome this problem, we used TBP, a volatile reductant, to reduce disulfide bonds of peptides in the digests so that the excess TBP can simply removed by vacuum evaporation $[15,27]$.

In this experiment, insulin was chosen as an example to test the methodology feasibility. After digestion by pepsin and reduced by TBP, peptides containing free cysteine residues were generated. Then, the sample was evaporated in vacuum to remove excess TBP. Subsequently, the protein digest sample was redissolved in solvent A and added with NPSP. Figure 5a is the ESSI-MS spectrum of digested insulin. Eight disulfide bond-containing peptides, NYCN/VCGERGF, NYCN/ VCGERGFF, ENYCN/VCGERGFF, QCCASVCSL/ FVNQHLCGSHL, NYCN/LVCGERGFF, GIVEQCCASVCSL/FVNQHLCGSHL, GIVEQCCASVCSL/ HLCGSHL, and NYCN/LVCGERGF (denoted as P1-P8, respectively, in the figure inset; the sequences before and after the slash indicate the two chains of the peptides) were present in the insulin peptic digest. In addition, peptides without disulfide bonds, such as YTPKA, ALY, GIVE, VEAL, FVNQ, YQLE, and QLENY, were also observed (see the list of detected peptide ions in the figure inset). After the reduction of disulfide bonds by TBP, all these peptides P1-P8 were reduced successfully and reduced peptides NYCN, VCGERGF, VCGERGFF, FVNQHLCGSHL, LVCGERGFF, GIVEQCCASVSCL, HLCGSHL, and LVCGERGF were observed, as expected (shown in Figure 5b). Two reduced peptides, ENYCN and QCCASVCSL, were not detected in the positive ion mode, probably due to either high acidities or the lack of basic residues. On the other hand, peptides without disulfide bonds (e.g., GIVE, VEAL, FVNQ, YTPKA, and QLENY) were insensitive to TBP reduction and remained intact. Two major peaks at $m / z 219\left([\mathrm{TBP}+\mathrm{O}+\mathrm{H}]^{+}\right)$and $437\left([2 \mathrm{TBP}+\mathrm{O}+\mathrm{H}]^{+}\right)$in Figure $5 \mathrm{~b}$ arose from the ionization of the oxidized TBP.

Figure $5 \mathrm{c}$ is the spectrum of the peptides detected after the NPSP derivatization. All the free thiol-containing peptides produced from the reduction of P1-P8 appear in Figure 5b (i.e., NYCN, VCGERGF, VCGERGFF, FVNQHLCGSHL, LVCGERGF, LVCGERGFF, GIVEQCCASVCSL, and HLCGSHL), and have acquired PhSetags from NPSP. The peak assignment was also confirmed by CID. For example, the single charged ion $\left[\mathrm{NYC}^{*} \mathrm{~N}+\mathrm{H}\right]^{+}$ $\left(m / z\right.$ 669) gave rise to fragment ions $\mathrm{b}_{3}$ and $\mathrm{y}_{3}$ and the doubly charged ion [FVNQHLC*GSHL $+2 \mathrm{H}]^{2+}(m / z$ 706) produced fragment ions $\mathrm{b}_{6}, \mathrm{~b}_{7}, \mathrm{~b}_{9}, \mathrm{y}_{4}, \mathrm{y}_{9}$, and $\mathrm{y}_{7}$. In particular, the peak at $\mathrm{m} / \mathrm{z} 1779$ corresponding to [GIVE$\left.\mathrm{QC}^{*} \mathrm{C}^{*} \mathrm{ASVC} * \mathrm{SL}+\mathrm{H}\right]^{+}$was detected (Figure $5 \mathrm{c}$ ), indicating that all the three thiols of the peptide GIVEQCCASVCSL were successfully modified simultaneously by NPSP. The $\mathrm{m} /$ $z 1779$ ion gave rise to fragment ions of $b_{10}, b_{11}$, and $b_{12}$ upon CID (Figure 2S-d, Supporting Information), confirming its structure. It is also noted that the $\mathrm{PhSe}$ - tags survive the CID process of [GIVEQC $\left.{ }^{*} \mathrm{C}^{*} \mathrm{ASVC} * \mathrm{SL}+\mathrm{H}\right]^{+}$, in agreement with our previous observation [14]. This phenomenon was also observed in CID spectra of other derivatized peptides (Figures 2S-a, b, and c, Supporting Information). This feature is useful in pinpointing the location of thiols in examined peptides. The successful derivatization of thiol peptides in the digest via the reaction with NPSP within $15 \mathrm{~s}$ emphasizes that NPSP is a very effective derivatization reagent.

Another tryptic digest of $\left[\mathrm{Arg}^{8}\right]$-conopressin $\mathrm{G}$ was also tested using the same approach and the reduced peptides were also modified by NPSP (Figures 3S, Supporting Information), further confirming the viability of the usage of NPSP as an alternative reagent for thiol protection in the bottom-up method. The resulting ion $\left[\mathrm{C}^{*} \mathrm{FIR}+\mathrm{H}\right]^{+}(\mathrm{m} / z$ 694) was confirmed by CID which showed the formation of fragment ions $\mathrm{b}_{2}, \mathrm{~b}_{3}, \mathrm{~b}_{4}, \mathrm{~b}_{4}-\mathrm{NH}_{3}, \mathrm{y}_{2}$, and $\mathrm{y}_{3}-\mathrm{NH}_{3}$. Another resulting ion $[\mathrm{NC} * \mathrm{PR}+\mathrm{H}]^{+}(\mathrm{m} / z 645)$ yielded fragment ions $\mathrm{b}_{3}-\mathrm{NH}_{3}, \mathrm{~b}_{4}, \mathrm{y}_{2}, \mathrm{y}_{2}-\mathrm{NH}_{3}, \mathrm{y}_{3}$, and $\mathrm{y}_{3}-\mathrm{NH}_{3}$, upon CID.

To further expedite the process for the reduction of protein digest, we also tested an electrolytic method to reduce disulfide bonds. Besides the benefit of greatly shortened reduction time, no chemicals were introduced into the sample solution; therefore this approach could dispense with removing excess reducing reagents. Recently we reported that online electrochemistry coupled with mass spectrometry can be used for fast structural analysis of proteins/peptides [28]. In this study, as a preliminary trial, we passed the insulin digest solution into an electrochemical cell for electrolytic reduction and then derivatize the resulting products using fast NPSP derivatization. We did observe some derivatized peptides such as $[\mathrm{FVNQHLC} * \mathrm{GSHL}+3 \mathrm{H}]^{3+}$ (Figure $4 \mathrm{~S}$, Supporting Information). As electrolysis is much faster than TBP reduction and takes only seconds, it would further expedite the whole process and eliminate a hazardous reagent from the protocol. Further investigation is underway.

\section{Conclusions}

NPSP is shown to be a premium thiol derivatization reagent. It reacts rapidly with protein/peptide thiols in seconds and allows a complete conversion of the free thiol groups with nearly stoichiometric amount of reagent. In addition, the NPSP reaction can be used to study thiol reactivity for obtaining structural and conformational information of proteins. The derivatization reaction is also applicable to protein enzymatic digests, suggesting its prospective application to the bottom-up proteomic approach. In this regard, the benefits include: (1) the derivatization step is faster than using traditional derivatizing reagents like iodoacetamide. Although the evaporation for the removal of excess amount of TBP takes time at this stage, it helps the ionization of the resulting products and it could be avoided if one replaces the 
chemical reduction by online fast electrochemical reduction; (2) the reaction of NPSP is highly selective and efficient; (3) the added tag via NPSP derivatization can survive the CID process, which is useful for locating thiols in peptides. Given the biological significance of thiols and the important features of selenylation reactions revealed in this study, it is expected that there will be many other applications of this thiol-selenium chemistry.

\section{Acknowledgments}

The authors gratefully acknowledge support of this work by NSF (CHE-0911160) and ASMS Research Award. In particular, the authors are thankful to Professor Michael L. Gross for the access to the NIH/NCRR Mass Spectrometry Resources at Washington University in St. Louis (grant number 2P41RR000954) and High-End Instrument Program of the NCRR (grant No. 1 S10 025101).

\section{References}

1. Meister, A., Anderson, M.E.: Glutathiemoone. Ann. Rev. Biochem. 52, 711-760 (1983)

2. Baty, J.W., Hampton, M.B., Winterbourn, C.C.: Proteomic detection of hydrogen peroxide-sensitive thiol proteins in jurkat cells. Biochem. J. 389, 785-795 (2005)

3. Sechi, S., Chait, B.T.: Modification of cysteine residues by alkylation. A tool in peptide mapping and protein identification. Anal. Chem 70, 5150-5158 (1998)

4. Moritz, R.L., Eddes, J.S., Reid, G.E., Simpson, R.J.: S-pyridylethylation of intact polyacrylamide gels and in situ digestion of electrophoretically separated proteins: a rapid mass spectrometric method for identifying cysteine-containing peptides. Electrophoresis 17, 907-917 (1996)

5. Cleland, W.W.: Dithiothreitol, a new protective reagent for SH groups. Biochemistry 3, 480-482 (1964)

6. Mendoza, V.L., Vachet, R.W.: Probing protein structure by amino acidspecific covalent labeling and mass spectrometry. Mass Spectrom. Rev. 28, 785-815 (2009)

7. Rogers, L.K., Leinweber, B.L., Smith, C.V.: Detection of reversible protein thiol modifications in tissues. Anal. Biochem. 358, 171-184 (2006)

8. Tokoroyama, T.: Discovery of the Michael reaction. Eur. J. Org. Chem. 10, 2009-2016 (2010)

9. Ishii, T., Fujioka, S., Sekiguchi, Y., Kotsuki, H.: A new class of chiral pyrrolidine-pridine conjugate base catalysts for use in asymmetric Michael addition reactions. J. Am. Chem. Soc. 126, 9558-9559 (2004)

10. Luo, S., Mi, X., Zhang, L., Liu, S., Xu, H., Cheng, J.: Functionalized chiral ionic liquids as highly efficient asymmetric organocatalysts for Michael addition to nitroolefins. Angew. Chem. Int. Ed. 45, 3093-3097 (2006)
11. Gilbert, H.F.: Thiol/disulfide exchange equilibria and disulfide bond stability. Method Enzymol. 251, 8-28 (1995)

12. Szajewski, R.P., Whitesides, G.M.: Rate constants and equilibrium constants for thiol-disulfide interchange reactions involving oxidized glutathione. J. Am. Chem. Soc. 102, 2011-2026 (1980)

13. Xu, K., Zhang, Y., Tang, B., Laskin, J., Roach, P., Chen, H.: Study of highly selective and efficient thiol derivatization using selenium reagents by mass spectrometry. Anal. Chem. 82, 6926-6932 (2010)

14. Zhang, Y., Zhang, H., Cui, W., Chen, H.: Tandem MS analysis of selenamide-derivatized peptide ions. J. Am. Soc. Mass Spectrom. 22, 1610-1621 (2011)

15. Dayon, L., Roussel, C., Girault, H.: Probing cysteine reactivity in proteins by mass spectrometric EC-tagging. J. Proteome Res. 5, 793800 (2006)

16. Takáts, Z., Wiseman, J.M., Gologan, B., Cooks, R.G.: Mass spectrometry sampling under ambient conditions with desorption electrospray ionization. Anal. Chem. 76, 4050-4058 (2004)

17. Zhang, Z., Marshall, A.: A universal algorithm for fast and automated charge state deconvolution of electrospray mass-to-charge ratio spectra. J. Am. Soc. Mass Spectrom. 9, 225-233 (1998)

18. Diedrich, J.K., Julian, R.R.: Site-selective fragmentation of peptides and proteins at quinone-modified cysteine residues investigated by ESI-MS. Anal. Chem. 82, 4006-4014 (2010)

19. Weerapana, E., Wang, C., Simon, G.M., Richter, F., Khare, S., Dillon, M.B.D., Bachovchin, D.A., Mowen, K., Baker, D., Cravatt, B.: Quantitative reactivity profiling predicts funtional cysteines in proteomics. Nature 468, 790-795 (2010)

20. Britto, P.J., Knipling, L., Wolff, J.: The local electrostatic environment determines cysteine reactivity of tubulin. J. Biol. Chem. 277, 2901829027 (2002)

21. Daggett, K.A., Sakmar, T.P.: Site-specific in vitro and in vivo incorporation of molecular probes to study G-protein-coupled receptors. Curr. Opin. Chem. Biol. 15, 392-398 (2011)

22. Miao, Z., Wu, S., Chen, H.: The study of protein conformation in solution via direct sampling by desorption electrospray ionization mass spectrometry. J. Am. Soc. Mass Spectrom. 21, 1730-1736 (2010)

23. Wang, H.R., Bai, J.H., Zheng, S.Y., Wang, Z.W., Zhou, H.M.: Ascertaining the number of essential thiol groups for the folding of creatine kinase. Biochem. Biophys. Res. Commun. 221, 174-180 (1996)

24. Rao, J.K., Bujacz, G., Wlodawer, A.: Crystal structure of rabbit muscle creatine kinase. FEBS Lett. 439, 133-137 (1998)

25. Fraczkiewicz, R., Braun, W.: Exact and efficient analytical calculation of the accessible surface areas and their gradients for macromolecules. J. Comp. Chem. 19, 319-333 (1998)

26. Gau, B.C., Chen, H., Zhang, Y., Gross, M.L.: Sulfate radical anion as a new reagent for fast photochemical oxidation of proteins. Anal. Chem. 82, 7821-7827 (2010)

27. Carru, C., Deiana, L., Sotgia, S., Pes, G.M., Zinellu, A.: Plasma thiols redox status by laser-induced fluorescence capillary electrophoresis. Electrophoresis 25, 882-889 (2004)

28. Zhang, Y., Dewald, H.D., Chen, H.: Online mass spectrometric analysis of proteins/peptides following electrolytic cleavage of disulfide bonds. J. Proteome Res. 10, 1293-1304 (2011) 